\title{
CURRENT STATE OF PUBLIC DEBT OF SUBJECTS OF THE RUSSIAN FEDERATION
}

\author{
(C) 2019 Popova Ekaterina Vitalievna \\ Postgraduate \\ Samara State University of Economics \\ E-mail: katirinna@mail.ru
}

Keywords: budget system, budgets of subjects, budget credits, public debt, debt sustainability, financial resources

The essence of the state debt of subjects of the Russian Federation is considered. The analysis of dynamics and structure of public debt of regions of Russia is carried out. The state debt and debt sustainability indicators of the Samara region are analyzed.

УДК 311

Код РИНЦ 06.00.00

\section{АНАЛИЗ ДИНАМИКИ, МОДЕЛИРОВАНИЕ И ПРОГНОЗИРОВАНИЕ ВЕЛИЧИНЫ ПРОЖИТОЧНОГО МИНИМУМА В РОССИЙСКОЙ ФЕДЕРАЦИИ}

\author{
(c) 2019 Савельева Татьяна Андреевна* \\ студент \\ Самарский государственный экономический университет \\ E-mail: taniu.saveljeva@yandex.ru
}

Ключевые слова: прожиточный минимум, потребительская корзина, анализ динамики, точечный прогноз, интервальный прогноз.

Статья посвящена анализу динамики ключевых индикаторов уровня жизни населения, а именно величины прожиточного минимума в среднем на душу населения и стоимости минимального набора продуктов питания. Анализ выполнен за период 2000-2018 годы. Автором представлены результаты эконометрического моделирования и прогнозирования в прикладном программном пакете "Gretl".

Прожиточный минимум используется в качестве ключевого вектора, определяющего уровень жизни населения. Опережающие темпы роста прожиточного минимума по сравнению с темпами роста доходов населения, обуславливают падение уровня жизни населения.

При формировании социальной политики в условиях кризисного состояния экономики, результатом которого становится падение жизненного уровня населения ориентируются непосредственно на оценку изменения величины прожиточного минимума, что

* Научный руководитель - Баканач Ольга Вячеславовна, кандидат экономических наук, доцент. 
безусловно актуализирует роль статистического инструментария в исследовании динамики величины прожиточного минимума.

Величина прожиточного минимума представляет собой стоимостную оценку потребительской корзины, а также обязательные платежи и сборы и рассчитывается ежеквартально Правительством Российской Федерации в целом по Российской Федерации 1 . Определение прожиточного минимума на уровне регионов проводится соответствующими органами исполнительной власти.

На графике (рис. 1) представлена динамика величины прожиточного минимума в среднем на душу населения за период 2000-2018 годы.

С 2000 года наблюдается тенденция к увеличению величины прожиточного минимума населения Российской Федерации, это связано, в первую очередь, с темпами роста цен, а не с желанием Правительства повысить благосостояние семей и граждан страны.

Динамика величины прожиточного минимума на душу населения в Российской Федерации свидетельствует о том, что за рассматриваемый период 2000-2018 гг. его величина составила 5414 руб. в среднем на душу населения. Каждый год данный показатель, в среднем, увеличивался на 504,3 руб. или на $12,6 \%$.

Для построения точечного прогноза на следующие 2 года (2019-2020 гг.) используется линейная функция тренда, поскольку она имеет наибольшую величину аппроксимации $\left(R^{2}=0,981\right)$.

Уравнение тренда имеет вид: $Y=549,12 X-77,158$

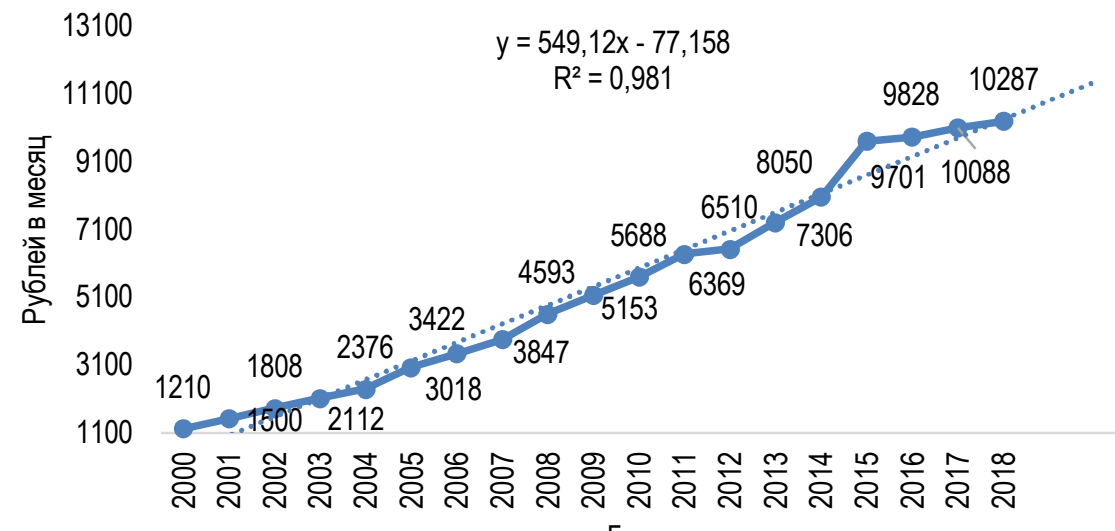

\section{Рис. 1. Величина прожиточного минимума в Российской Федерации в среднем на душу населения за 2000-2018 годы}

Результаты точечного прогноза следующие: величина прожиточного минимума в Российской Федерации в среднем на душу населения составит в 2019 году- 10905,24 руб. в месяц, а в 2020 году- 11454,36 руб. в месяц.

В прикладном программном пакете "Gretl" для эконометрического анализа произведено построение интервального прогноза. 
С достоверностью 95\% прогнозное значение на 2019 год находится в интервале от 9963,67 руб. в месяц до 11846,70 руб. в месяц; на 2020 год находится в интервале от 10502,77 руб. до 12405,84 руб. в месяц.

При анализе прожиточного минимума особое внимание следует уделить потребительской корзине. В ее состав входит минимальный набор продуктов питания для обеспечения основных жизненных функций человека при сохранении его здоровья и непродовольственные товары и услуги. Стоимость непродовольственных товаров и услуг соотносится со стоимостью продуктов поровну. Потребительская корзина для основных социально-демографических групп населения в целом по Российской Федерации устанавливается не реже одного раза в пять лет ${ }^{2}$.

Росстатом ежемесячно публикуются данные о стоимости условного (минимального) набора продуктов питания по России в целом³. Вид графика изменения значений этого показателя (рис. 2) показывает наличие сезонной компоненты, а также позволяет пронаблюдать возрастающую тенденцию в конце года и к снижению в перспективе.

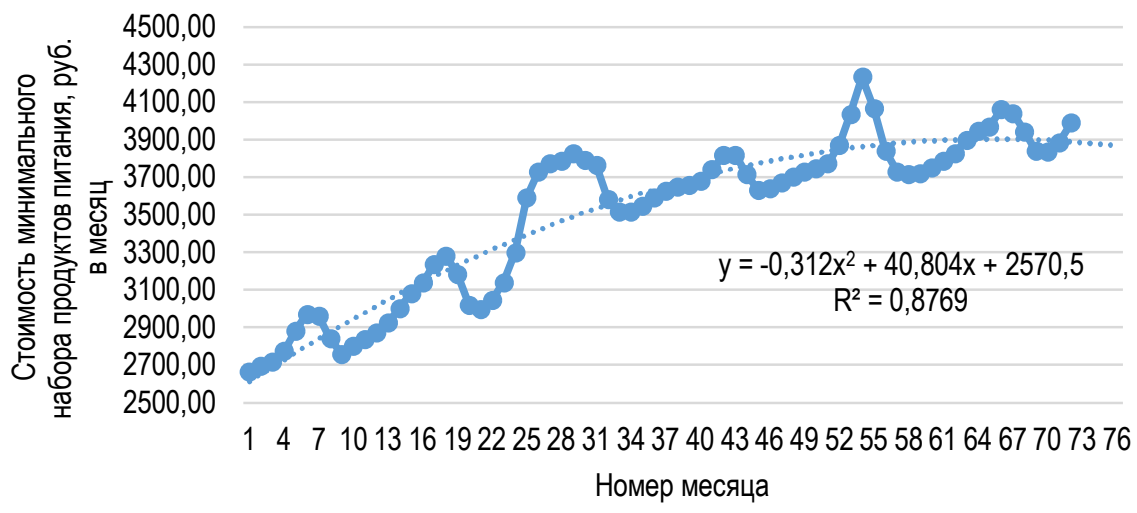

Рис. 2. Динамика стоимости условного (минимального) набора продуктов питания в расчете на одного человека в месяц по Российской Федерации

За исследуемый период января 2000 г. - декабрь 2018 г. величина показателя составила 3509,44 руб. (в среднемесячном исчислении на одного человека). Ежемесячный средний прирост составлял 18,7 руб. или $0,6 \%$.

Для построения точечного прогноза на следующий квартал, то есть 4 месяца вперёд (с января по апрель 2019 года) используется полиномиальная линия тренда, $R^{2}=$ 0,8769, наилучшая аппроксимация.

Уравнение тренда имеет вид: $Y=-0,312 X 2+40,804 X+2570,5$

Результаты точечного прогноза следующие: стоимость минимального набора продуктов питания по России в целом в расчете на одного человека в месяц составит в январе - 3886,5 руб.; в феврале- 3881,5 руб.; в марте- 3875,8 руб.; в апреле- 3869,492 руб.

B прикладном программном пакете "Gretl" для эконометрического анализа произведено построение интервального прогноза ${ }^{4}$. 
С достоверностью 95\% прогнозное значение на январь находится в интервале от 3701,866 руб. до 4513,579 рублей; на февраль- от 3718,275 руб. до 4530,729 рублей; на март- от 3734,673 руб. до 4547,890 руб.; на апрель прогнозное значение находится в интервале от 3751,061 руб. - 4565,062 руб.

Оценку сезонной составляющей проведем при помощи индекса сезонности 5

$$
\mathrm{I}_{\mathrm{S}}=\frac{\overline{\mathrm{y}_{\mathrm{i}}}}{\overline{\mathrm{y}_{\mathrm{i}}^{\prime}}} \cdot 100,
$$

где $\overline{y_{i}}$ - средняя из фактических уровней одноименных месяцев;

$\overline{y_{i}^{\prime}}$ - средняя из выравненных значений по уравнению тренда уровней одноименных месяцев.

Сезонная волна представлена на рис. 3.

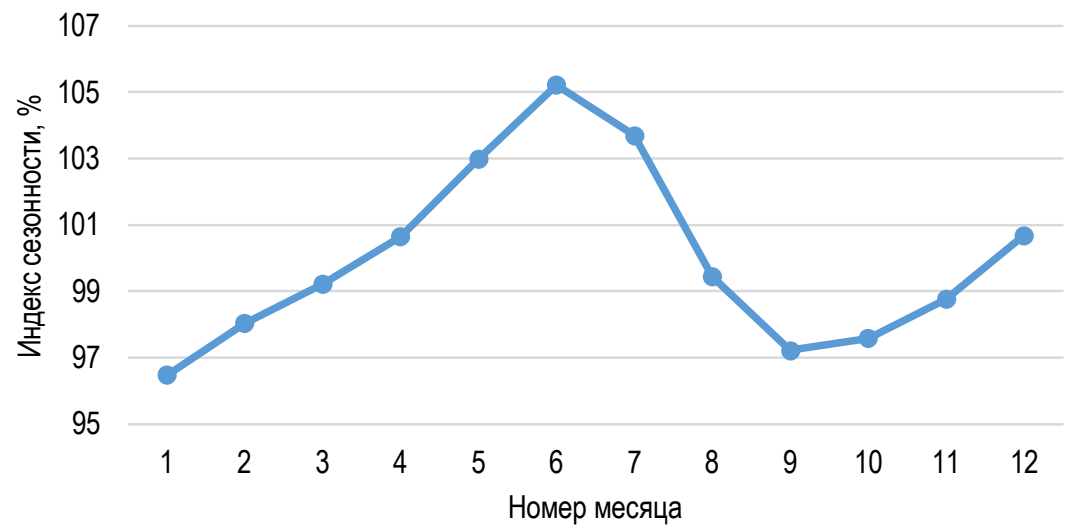

Рис. 3. Сезонная волна в динамике стоимости минимального набора основных продуктов питания

На графике четко прослеживается сезонность в динамике стоимости набора, а именно наблюдается ежегодное увеличение его стоимости, высшая точка приходится на май-июнь, а падение на первые месяцы осени - сентябрь и октябрь.

1 Федеральный закон от 24 октября 1997 г. N 134-Ф3 "О прожиточном минимуме в Российской Федерации" с изменениями и дополнениями от 1 апреля 2019 года, действующий в настоящее время - [Электронный ресурс] - Режим доступа: https://base.garant.ru/172780/

2 Федеральный закон "О потребительской корзине в целом по Российской Федерации" от 03.12.2012 N 227-Ф3 (последняя редакция)

3 Официальный сайт Федеральная служба государственной статистики - [Электронный ресурс] - Режим доступа: http://www.gks.ru/

${ }^{4}$ Малова A.C. Основы эконометрики в среде GRETL. Учебное пособие / А.С. Малова - ИД Проспект, 2018.- 112 с.

5 Елисеева, И. И. Статистика: [углубленный курс]: учебник для бакалавров / И. И. Елисеева и др.]. - Москва: Юрайт: ИД Юрайт, 2016. - 565 с. 


\title{
ANALYSIS OF THE DYNAMICS, MODELLING AND FORECASTING OF THE SUBSISTENCE MINIMUM IN THE RUSSIAN FEDERATION
}

\author{
(C) 2019 Savelyeva Tatyana Andreevna \\ Student \\ Samara State University of Economics \\ E-mail: taniu.saveljeva@yandex.ru
} forecast

Keywords: subsistence minimum, consumer basket, dynamics analysis, point forecast, interval

Article is devoted to the analysis of dynamics of key level meters of life of the population, namely value of a living wage on average per capita and costs of the minimum set of food. The analysis is made during 2000-2018. The author presented results of econometric modeling and forecasting in the applied Gretl software package.

УДК 336

Код РИНЦ 06.00.00

\section{ПЛАНИРОВАНИЕ И ОПТИМИЗАЦИЯ ДЕНЕЖНЫХ ПОТОКОВ БАНКА}

\author{
() 2019 Сальникова Анна Сергевна \\ студент \\ (C) 2019 Дождева Елена Евгеньевна \\ кандидат экономических наук, доцент \\ Самарский государственный экономический университет \\ E-mail: ud1173@yandex.ru
}

Ключевые слова: денежные потоки, движение денежных средств, чистый денежный поток, оптимизация денежных потоков банка, планирование денежных потоков банка.

Статья посвящена анализу таких понятий, как планирование и оптимизация денежных потоков банка, Эффективность управления денежными потоками банка во много зависят от сбалансированности денежных потоков. Важным средством улучшения сбалансированности является оптимизация денежных потоков банка. Данная тема является актуальной, так как правильно организованные денежные потоки являются предпосылкой достижения высоких финансовых результатов деятельности банка.

В современной экономике весьма актуальной проблемой является организация движения денежных потоков банка. Денежный поток, есть величина, измеряемая в процессе формирования, распределения и использования денежных средств компании. Специалисты ${ }^{1}$ считают, что денежный поток представляет собой индикатор будущих финансовых возможностей организации. При этом, приоритетной задачей банка является анализ и постановка эффективной системы управления денежными потоками. По 